\title{
Original article \\ Shelf-life extension and quality improvement of a Portuguese traditional ready-to-eat meat product with vinegar
}

\author{
Marta Laranjo, ${ }^{1,2}$ Maria Eduarda Potes, ${ }^{1,3}$ Ana Gomes, ${ }^{4}$ Joana Véstia, ${ }^{1}$ Raquel Garcia, ${ }^{1,2,5}$ Maria José Fernandes, ${ }^{6}$ \\ Maria João Fraqueza ${ }^{6}$ (iD) \& Miguel Elias ${ }^{1,4 *}$ iD \\ 1 ICAAM-Instituto de Ciências Agrárias e Ambientais Mediterrânicas, Universidade de Évora, Pólo da Mitra, Ap. 94, 7006-554 Évora, \\ Portugal \\ 2 IIFA-Instituto de Investigação e Formação Avançada, Universidade de Évora, Ap. 94, 7006-554 Évora, Portugal \\ 3 Departamento de Medicina Veterinária, Escola de Ciências e Tecnologia, Universidade de Évora, Pólo da Mitra, Ap. 94, 7006-554 Évora, \\ Portugal \\ 4 Departamento de Fitotecnia, Escola de Ciências e Tecnologia, Universidade de Évora, Pólo da Mitra, Ap. 94, $7006-554$ Évora, Portugal \\ 5 LAQV, REQUIMTE, Departamento de Química, Faculdade de Ciências e Tecnologia, Universidade Nova de Lisboa, 2829-516 Caparica, \\ Portugal \\ 6 CIISA-Centro de Investigação Interdisciplinar em Sanidade Animal, Faculdade de Medicina Veterinária, Universidade de Lisboa, Av. da \\ Universidade Técnica, Pólo Universitário, Alto da Ajuda, 1300-477 Lisboa, Portugal
}

(Received 26 March 2018; Accepted in revised form 15 July 2018)

Summary Cabeça de xara is a traditional ready-to-eat meat product (RTEMP) from the Portuguese region of Alentejo. It is a moulded galantine made of low value pork pieces. The aim of this work was to test the addition of vinegar in reducing the spoilage microbiota, as well as controlling Listeria monocytogenes, in order to increase the shelf-life of cabeça de xara. Physicochemical (fatty acids and biogenic amines profiles), microbiological (mesophiles, psychrotrophic bacteria, enterobacteria, yeasts and L. monocytogenes) and sensory analyses were performed throughout the storage period. RTEMP vinegar samples always showed lower microbiological counts than control samples. Moreover, RTEMP vinegar samples showed significantly lower contents in vasoactive amines throughout the storage period, which might be explained by their significantly lower enterobacteria counts. Concerning sensory analysis, RTEMP vinegar samples generally scored higher in overall appreciation. Our results showed that shelf-life of cabeça de xara may be extended from 1 to 3 months.

Keywords Biogenic amines, fatty acids, galantine, Listeria monocytogenes, ready-to-eat food, sensory quality, vinegar.

\section{Introduction}

Cabeça de xara is a ready-to-eat meat product (RTEMP), whose production is very characteristic in a particular region of Portugal, Alentejo. It is a galantine usually moulded into semicylindrical shape made with various pork meat pieces, namely deboned pork heads, tongue and cartilaginous tissue to which a number of condiments like salt, parsley, wine and pepper are added. The usual shelf-life period of cabeça de xara is 1 month.

The use of food additives in the food industry has promoted important developments to ensure the food safety, stability and quality. However, notwithstanding their clear benefit, consumers are increasingly concerned about the use of chemical additives.

*Correspondent: E-mail: elias@uevora.pt
Alternatively, naturally occurring compounds have been investigated as replacements for conventional additives. These are compounds derived from natural sources such as spices, fruits, vegetables and oil, which are 'Generally Recognised As Safe' (GRAS) where oregano (Origanum vulgare L.), rosemary (Rosmarinus officinalis L.), clove (Syzygium aromaticum L.), garlic, grape seed extract and marjoram (Origanum majorana L.) are just a few examples (Tajkarimi et al., 2010; Xi et al., 2011a, 2012; García-Díez et al., 2016, 2017). Very encouraging results have arisen with the use of organic additives as regards the containment of various pathogens including Escherichia coli, Salmonella Typhimurium, Listeria monocytogenes (Over et al., 2009; Shan et al., 2009; Cui et al., 2010).

Following this line of research into the use of natural antimicrobial ingredients, vinegar has been standing out 
for its antimicrobial effect. Vinegar is an inexpensive natural additive with no side effects, easy to obtain and manipulate. It is a fermented product with several active compounds. Those with antimicrobial effects are organic acids, polyphenols and melanoidins (Chen et al., 2016). This is an ingredient whose use dates back to ancient times for its preservative properties, as well as for its aroma. The fact that acetic acid is considered as a GRAS substance (Chang \& Fang, 2007) has also contributed to the increasing interest in studies of its efficacy in reducing the number of foodborne pathogens. Acetic acid, in its protonated form, is able to pass through the membrane and diffuse into the bacterial cells (Budak et al., 2014). Its effect consists in destroying the outer membrane of bacteria, inhibiting macromolecular synthesis, consuming energy, increasing intracellular osmotic pressure and promoting the generation of antibacterial peptides in host cells (Chen et al., 2016).

Regarding meat products, one of the most common applications of acetic acid has been to eliminate or prevent the development of L. monocytogenes, a challenging foodborne bacterium causing severe foodborne diseases (Barbuddhe et al., 2012; Mateus et al., 2014). It is resistant to low $\mathrm{pH}$, as well as extreme temperatures (between $-0.4{ }^{\circ} \mathrm{C}$ and $45^{\circ} \mathrm{C}$; Xi et al., 2011b).

Positive results have been obtained in the reduction of pathogens by acetic acid alone or in combination with other natural antimicrobial agents. For example, a reduction in L. monocytogenes counts was observed by $\mathrm{Xi}$ et al. (2012) in frankfurter sausages naturally cured by mixing powdered vinegar, lime and cherry.

This aim of the present work was to use vinegar to improve food quality through a better control of spoilage, safety and sensory acceptability, of a traditional RTEMP. More detailed objectives included the nutritional characterisation and shelf-life extension of cabeça de xara, by reducing spoilage microorganisms and controlling the pathogenic L. monocytogenes.

\section{Materials and methods}

\section{Cabeça de xara manufacture}

Cabeça de xara, a Portuguese traditional meat product characteristic of the Alentejo region, was manufactured from the head muscles, tongue and cartilaginous tissue of hybrid Iberian x Duroc pigs. First, the heads were thoroughly washed and covered with a layer of a mixture consisting of salt, sugar and nitrite and allowed to stand, for seasoning purposes, for 5 days at a temperature of $2{ }^{\circ} \mathrm{C}$. After this period, the heads were cooked at $105^{\circ} \mathrm{C}$ for $10 \mathrm{~min}$ in water previously seasoned with white wine, salt, parsley, black and white pepper, marjoram and cloves. The heads were then deboned and coarsely cut and again heated at
$80{ }^{\circ} \mathrm{C}$ in the cooking water for $10 \mathrm{~min}$, placed in metallic semicylindrical moulds (with $40 \mathrm{~cm}$ length and $14 \mathrm{~cm}$ height) and kept under refrigeration $\left(0-5{ }^{\circ} \mathrm{C}\right)$ for 48 h. Afterwards, cabeça de xara was demoulded. Before packaging, cabeça de xara was sliced and subjected to two treatments: control samples were submerged in water while vinegar samples were submerged in a $50 \%(\mathrm{v} / \mathrm{v})$ aqueous solution of white wine vinegar containing 6\% acetic acid (Paladin, Mendes Gonçalves, Portugal), at room temperature, for 5 min. At last, all samples were vacuum packed in a 700 STE-XL equipment (Turbovac, The Netherlands) using polyamide/polyethylene co-extruded film packages (Alempack, Portugal) and stored at low temperature (between 0 and $5{ }^{\circ} \mathrm{C}$ ) for 3 months.

Three independent batches were prepared for each treatment. Two samples per treatment from each batch were collected throughout the storage period.

\section{Physicochemical analyses}

The proximate composition of cabeça de xara samples was analysed as described before (Laranjo et al., 2016b) following the standard methodologies for moisture content ISO 1442 (1997), total ash ISO 936 (1998), crude protein ISO 937 (1978) and total fat content ISO 1443 (1973). Furthermore, the 'Atwater factors' were the energy conversion factors used for proteins, lipids and carbohydrates, for calorie count, respectively 4, 9 and $4 \mathrm{kcal} \mathrm{g}^{-1}$ (Kim \& Choi, 2015). These are considered the EU reference values to determine energy values, as recommended in the in the 1169/2011 Commission Regulation (EC 2011).

For $\mathrm{pH}$ assessment, procedures described in the standard method ISO 2917 were followed (1999). Measurements were accomplished with a Crison 507 (Barcelona, Spain) pH-meter. Water activity $\left(\mathrm{a}_{\mathrm{W}}\right)$ was determined with a hygrometer (Hygroskop Rotronic DT, Zurich, Switzerland) equipped with a WA-40 probe at $25^{\circ} \mathrm{C}$. Total basic volatile nitrogen (TBV-N) was determined as described before (Fraqueza et al., 2008) and peroxide values were determined according to ISO 3960 (2017a).

\section{Microbiological analysis}

The following microbiological parameters were analysed as described before (Laranjo et al., 2015) and according to the corresponding international standard methods: total mesophilic bacteria ISO 4833-1 (2013), psychrotrophic bacteria ISO 17410 (2001), enterobacteria ISO 21528-2 (2017b), yeasts and moulds ISO 215271 (2008) and L. monocytogenes ISO 11290-2 (2014). Anaerobic psychrotrophic bacteria were counted in Tryptone Glucose Extract (TGE; Scharlau) kept under anaerobic conditions, in an anaerobic jar (Merck) using 
Anaerocult ${ }^{\circledR} \mathrm{A}$ (Merck) and incubated at $10^{\circ} \mathrm{C}$ for 7 days.

\section{Biogenic amines analysis}

Biogenic amines extraction and quantification was performed following the analytical protocol described by Laranjo et al. (2016a).

\section{Fatty acids profile}

Samples were mechanically homogenised, lyophilised and stored at $4{ }^{\circ} \mathrm{C}$ in glass flasks until further analysis. Fatty acids were extracted as described by Laranjo et al. (2015). Identification of Fatty Acids Methyl Esthers (FAMEs) was based on comparison of retention times of known composition standards mixtures (37-component FAME mix, Supelco).

\section{Sensory evaluation}

A trained panel of 10 qualified assessors (five women and five men) were selected according to ISO 8586-1 (1993). Products sensory evaluation took place in a room especially prepared for that purpose following the methodology previously described (Costell \& Durán, 1981a,b,c,d). Thirty minutes prior each session, cabeça de xara samples were sliced (5 mm thick) and three slices were randomly disposed in white dishes. Each dish was identified with a three digit number. Moreover, neutral water and crackers were also provided so tasters could rinse their mouths between evaluations. Each sample was rated in triplicate, during different sessions. Tasters were asked to rate samples colour intensity, off colour, aroma intensity, off aroma, hardness, succulence, flavour intensity, off flavour, salt perception and overall acceptability based on a 0 ('minimum perception') to 100 ('maximum perception') scale. Salt perception was the exception, where $50 \%$ corresponding to the optimum value. In this case, lower rates would indicate a low salt perception while higher rates would correspond to high salt contents.

\section{Statistical analysis}

Results were analysed according to ANOvA using Statistica $^{\mathrm{TM}}$ v.7.0, software from Statsoft (StatSoft Inc, Palo Alto, CA, USA, 1984-2007). Significant differences $(P<0.05)$ were identified based on Tukey Honest Significant Difference (HSD) test.

\section{Results and discussion}

In the present study, the quality of cabeça de xara was assessed according to its $\mathrm{pH}$ and $\mathrm{a}_{\mathrm{w}}$, main factors responsible for product stability and influencing spoilage and potential pathogenic bacteria multiplication during storage as well its sensory acceptability. Furthermore, this RTEMP was evaluated regarding nutritional components through the determination of its proximate composition and the analysis of fatty acids profile.

\section{Nutritional characterisation of cabeça de xara}

Table 1 shows the proximate composition of cabeça de xara, evidencing no significant differences between control and vinegar samples. This is a high moisture meat product (57.9-59.9\%), whose major fraction is lipids, followed by proteins.

Oleic acid (C18:1) accounts for the major proportion of the lipid fraction (Table 2), followed by palmitic $(\mathrm{C} 16: 0)$, stearic $(\mathrm{C} 18: 0)$ and linoleic $(\mathrm{C} 18: 2)$. All other fatty acids are present only in small quantities $(<10 \%)$. This is in accordance with the fatty acid profile reported for other pork meat products (Elias, 2004). Unsaturated fatty acids (MUFA and PUFA) are predominant over saturated fatty acids, with MUFA accounting for over $50 \%$ of the total lipid fraction. The PUFA/SFA $(\mathrm{P} / \mathrm{S})$ ratio should be above 0.4 , while the normal $\mathrm{P} / \mathrm{S}$ ratio of meat is approximately 0.1 (Wood et al., 2003), which means that our results although below the recommended values are all above the usual ratio. Regarding the MUFA+PUFA/SFA $(\mathrm{U} / \mathrm{S})$ ratio, although we found no reference values, our results are around 2.0, which may be considered a favourable ratio. Correspondingly, Elias (2004) found $\mathrm{U} / \mathrm{S}$ ratios between 1.6 and 1.7 for dry-cured pork meat sausages.

Regarding fatty acids composition, no significant differences were observed between treatments or throughout storage (Table 2). No differences were expected with the addition of vinegar, but degradation of fatty acids could occur with time, although it was not probable, because the samples were vacuum packaged. The effect of fatty acids on shelf-life may be explained by the susceptibility of unsaturated fatty

Table 1 One-way Anova for proximate composition (g/100 g)

\begin{tabular}{lccl}
\hline & \multicolumn{2}{l}{ Treatment } & \\
\cline { 2 - 3 } & \multicolumn{1}{c}{ Control } & Vinegar & Significance \\
\hline Moisture & $59.9 \pm 3.6$ & $57.9 \pm 4.1$ & $\mathrm{~ns}$ \\
Fat & $19.2 \pm 5.0$ & $22.8 \pm 5.7$ & $\mathrm{~ns}$ \\
Protein & $16.75 \pm 2.55$ & $16.42 \pm 1.86$ & $\mathrm{~ns}$ \\
Carbohydrates & $1.7 \pm 1.9$ & $0.6 \pm 0.5$ & $\mathrm{~ns}$ \\
Ash & $2.35 \pm 0.38$ & $2.34 \pm 0.33$ & $\mathrm{~ns}$ \\
Energy (kcal/100 g) & $247 \pm 40$ & $274 \pm 45$ & $\mathrm{~ns}$ \\
Energy (kJ/100 g) & $1032 \pm 166$ & $1143 \pm 190$ & $\mathrm{~ns}$ \\
\hline
\end{tabular}

Data are shown as means \pm standard deviation.

ns, not significant at $P<0.05$. 
Table 2 Fatty acids composition ( $\%$ of total fatty acids)

\begin{tabular}{|c|c|c|c|c|c|c|c|c|}
\hline \multirow{2}{*}{$\begin{array}{l}\text { Treatment } \\
\text { Storage time (months) }\end{array}$} & \multicolumn{4}{|l|}{ Control } & \multicolumn{4}{|l|}{ Vinegar } \\
\hline & 0 & 1 & 2 & 3 & 0 & 1 & 2 & 3 \\
\hline C12:0 & $0.24 \pm 0.11$ & $0.18 \pm 0.10$ & $0.21 \pm 0.13$ & $0.22 \pm 0.11$ & $0.26 \pm 0.20$ & $0.16 \pm 0.09$ & $0.27 \pm 0.15$ & $0.25 \pm 0.11$ \\
\hline C14:0 & $1.93 \pm 0.54$ & $2.17 \pm 0.62$ & $2.45 \pm 1.15$ & $1.89 \pm 2.06$ & $2.18 \pm 1.20$ & $2.13 \pm 0.62$ & $2.07 \pm 2.06$ & $1.64 \pm 0.97$ \\
\hline C16:0 & $18.94 \pm 1.19$ & $19.43 \pm 1.60$ & $19.99 \pm 2.97$ & $19.35 \pm 0.67$ & $18.41 \pm 0.91$ & $20.34 \pm 2.77$ & $19.04 \pm 0.61$ & $19.13 \pm 1.37$ \\
\hline C16:1 & $3.23 \pm 0.61$ & $3.17 \pm 0.60$ & $3.67 \pm 0.70$ & $2.92 \pm 0.66$ & $3.16 \pm 0.67$ & $3.12 \pm 0.45$ & $3.14 \pm 0.58$ & $3.27 \pm 0.62$ \\
\hline C17:0 & $0.28 \pm 0.05$ & $0.28 \pm 0.04$ & $0.25 \pm 0.08$ & $0.24 \pm 0.10$ & $0.25 \pm 0.03$ & $0.28 \pm 0.05$ & $0.28 \pm 0.05$ & $0.26 \pm 0.05$ \\
\hline C17:1 & $0.38 \pm 0.05$ & $0.39 \pm 0.03$ & $0.37 \pm 0.05$ & $0.30 \pm 0.12$ & $0.36 \pm 0.05$ & $0.39 \pm 0.04$ & $0.38 \pm 0.04$ & $0.36 \pm 0.05$ \\
\hline C18:0 & $8.15 \pm 1.55$ & $8.29 \pm 1.98$ & $8.35 \pm 2.29$ & $8.72 \pm 1.33$ & $7.64 \pm 1.49$ & $5.95 \pm 2.43$ & $8.13 \pm 1.22$ & $7.82 \pm 1.81$ \\
\hline C18:1 & $47.40 \pm 0.73$ & $49.36 \pm 2.70$ & $47.47 \pm 3.28$ & $46.72 \pm 1.15$ & $48.82 \pm 0.90$ & $48.68 \pm 6.57$ & $47.54 \pm 2.40$ & $48.91 \pm 1.42$ \\
\hline C18:2 & $5.40 \pm 1.12$ & $5.66 \pm 0.76$ & $5.31 \pm 1.86$ & $4.99 \pm 1.01$ & $5.46 \pm 1.35$ & $6.55 \pm 2.99$ & $5.16 \pm 0.94$ & $5.58 \pm 1.22$ \\
\hline C18:3 & $1.75 \pm 0.35$ & $1.68 \pm 0.21$ & $1.80 \pm 0.33$ & $1.64 \pm 0.33$ & $1.73 \pm 0.25$ & $1.77 \pm 0.23$ & $1.52 \pm 0.11$ & $1.64 \pm 0.28$ \\
\hline$C 20: 1$ & $0.73 \pm 0.25$ & $0.65 \pm 0.08$ & $0.62 \pm 0.10$ & $0.63 \pm 0.36$ & $0.64 \pm 0.07$ & $0.67 \pm 0.22$ & $0.62 \pm 0.09$ & $0.61 \pm 0.08$ \\
\hline$C 21: 1$ & $0.82 \pm 0.37$ & $0.53 \pm 0.17$ & $0.74 \pm 0.38$ & $0.93 \pm 0.41$ & $0.62 \pm 0.22$ & $0.58 \pm 0.32$ & $0.80 \pm 0.33$ & $0.56 \pm 0.09$ \\
\hline MUFA & $52.56 \pm 2.01$ & $54.10 \pm 3.58$ & $52.87 \pm 4.51$ & $51.50 \pm 2.70$ & $53.60 \pm 1.91$ & $53.44 \pm 7.60$ & $52.48 \pm 3.44$ & $53.71 \pm 2.26$ \\
\hline PUFA & $7.15 \pm 1.47$ & $7.34 \pm 0.97$ & $7.11 \pm 2.19$ & $6.63 \pm 1.34$ & $7.19 \pm 1.60$ & $8.32 \pm 3.22$ & $6.68 \pm 1.05$ & $7.22 \pm 1.50$ \\
\hline SFA & $29.54 \pm 3.44$ & $30.35 \pm 4.34$ & $31.25 \pm 6.62$ & $30.42 \pm 4.27$ & $28.74 \pm 3.83$ & $28.86 \pm 5.96$ & $29.79 \pm 4.09$ & $29.10 \pm 4.31$ \\
\hline $\mathrm{P} / \mathrm{S}$ & $0.24 \pm 0.43$ & $0.24 \pm 0.22$ & $0.23 \pm 0.33$ & $0.22 \pm 0.31$ & $0.25 \pm 0.42$ & $0.29 \pm 0.54$ & $0.22 \pm 0.26$ & $0.25 \pm 0.35$ \\
\hline $\mathrm{U} / \mathrm{S}$ & $2.02 \pm 1.01$ & $2.02 \pm 1.05$ & $1.92 \pm 1.01$ & $1.91 \pm 0.95$ & $2.12 \pm 0.92$ & $2.14 \pm 1.82$ & $1.99 \pm 1.10$ & $2.09 \pm 0.87$ \\
\hline
\end{tabular}

MUFA, Monounsaturated Fatty Acids; PUFA, Polyunsaturated Fatty Acids; SFA, Saturated Fatty Acids. P/S, PUFA/SFA ratio; U/S, Unsaturated (MUFA + PUFA)/SFA ratio.

Data are expressed as mean $\% \pm$ standard deviation.

acids (UFA) to oxidation, leading to the development of rancidity with time (Wood et al., 2003).

\section{Spoilage and safety of cabeça de xara}

The spoilage and safety of cabeça de xara during storage at low temperature was evaluated though microbiological analyses, TBV-N and peroxide content and the profile and content in biogenic amines.

The control of the product's stability throughout storage was accessed through the determination of $\mathrm{pH}$ and $\mathrm{a}_{\mathrm{W}}$ values.

$\mathrm{pH}$ significantly differs with treatment $(P<0.001)$, with lower values in the samples containing vinegar (Table 3$)$, and throughout storage $(P<0.05)$. Regarding $\mathrm{a}_{\mathrm{w}}$, the values were from 0.979 to 0.987 , with no significant differences between samples (Table 3). These results suggest that cabeça de xara may be a more stable product than other galantines (containing fish and pork), which had higher $\mathrm{pH}$ values and similar $\mathrm{a}_{\mathrm{W}}$ values (Herrero et al., 2008).

The content in total basic volatile nitrogen (TBV-N) shows significant differences between treatments $(P<0.001)$, with the vinegar treated samples showing lower values. Furthermore, the TBV-N values significantly increase throughout storage $(P<0.001)$ (Table 3), which is more consistent in control samples. This increase in TBV-N values essentially corresponds to an increase in nitrogen compounds resulting from the deterioration caused by bacteria. No significant differences were found for peroxide values, although an increasing trend was observed with storage time, which is more pronounced from the second to the third month.

\section{Microbiological results}

Significant differences were observed between cabeça de xara treatments for mesophiles $(P<0.01)$, psychrotrophic $(P<0.001)$ and anaerobic psychrotrophic $(P<0.001)$ bacteria, enterobacteria $(P<0.001)$ and L. monocytogenes $(P<0.05$; Table 4$)$. Control samples always showed higher microbial counts than RTEMP vinegar samples.

Regarding storage time, there is an increase in log $\mathrm{cfu}^{-1}$ for all microbial groups until 2 months of RTEMP storage, followed by a slight decrease from the second to the third month, mainly in enterobacteria $(P<0.001$; Table 4$)$. Comparing RTEMP control and vinegar samples, the increase from 0 to 3 months was about one $\log \mathrm{cfu} \mathrm{g}^{-1}$ less in RTEMP vinegar samples, with the maximum difference $\left(3 \log \mathrm{cfu} \mathrm{g}^{-1}\right)$ in enterobacteria.

The rapid increase in the first month suggests that there was a post contamination after thermal treatment, probably due to cross-contamination from operators or industrial surfaces during product moulding and demoulding. On the other hand, the decrease from the second to the third month could be explained through both the decrease in $\mathrm{pH}$ by the production of organic acids, such as lactic acid, and the increasing 

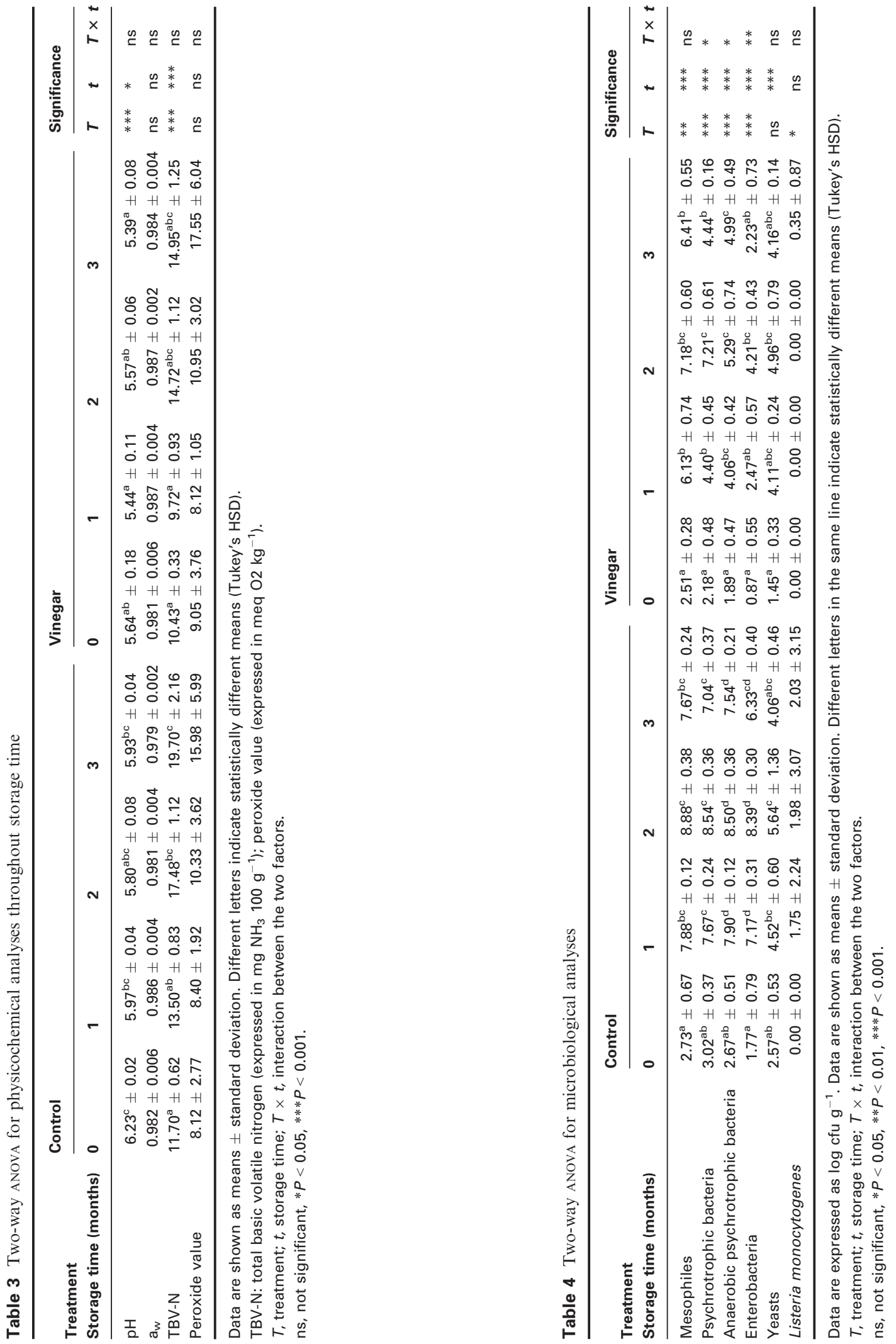
trend in peroxides. However, when peroxides accumulate, they inhibit the microbiota, mainly enterobacteria.

The slight decrease in $\mathrm{pH}$ throughout storage may be due to the TBV-N buffer effect, which limits $\mathrm{pH}$ variations. The increase in the microbiota with storage time may also have contributed to this decrease in $\mathrm{pH}$ through the production of organic acids, such as lactic acid among others. Since these acids are mainly in the undissociated form, their effect is hardly noticed in the $\mathrm{pH}$ value. However, these organic acids may have an antimicrobial effect over several microbial groups, mostly in enterobacteria.

The growth of psychrotrophic and anaerobic psychrotrophic bacteria was also less pronounced in RTEMP vinegar samples than in control samples. This is in agreement with Stelzleni et al. (2013), which concluded that the addition of vinegar to ground beef patties was effective in controlling the growth of psychrotrophic organisms, such as L. monocytogenes.

Listeria monocytogenes was present from the first month on but only in control batch 1 . However, it was inhibited by the addition of vinegar until the third month of storage, where L. monocytogenes was present but below the limit established in the 1441/2007 Commission Regulation (EC 2007). The other two batches were free from contamination with L. monocytogenes throughout the assayed storage period (Table 4). L. monocytogenes is a pathogen that tolerates cold temperatures and poses a potential health risk for ready-to-eat meat based products that are typically stored under refrigeration (Zhang et al., 2009; Henriques et al., 2017).

Organic acids, such as acetic acid (vinegar) are more effective against psychrotrophic bacteria, such as L. monocytogenes, than mesophiles (Smulders \& Greer, 1998), which may explain the higher reduction (2.5 log $\mathrm{cfu}^{-1}$ ) observed in psychrotrophic and psychrotrophic anaerobic bacteria than in mesophiles (Table 4). The deleterious effect of vinegar on L. monocytogenes, a psychrotrophic bacterium, can also explain why it could not be detected until the third month of storage, while in control samples it was already detected after 1 month of storage.

The major microbiological concerns associated with these products focus on two types of microorganisms, psychrotrophic and mesophilic, which may grow during extended refrigerated storage or temperature abuse, and cause food spoilage. European or Portuguese legislation that applies to these kind of meat products considers only the safety indicator Listeria monocytogenes since was previously submitted to a thermic treatment. Therefore, we refer to the Irish guidelines (FSAI 2016), which include hygiene criteria. According to the 'Guidelines for the Interpretation of Results of Microbiological Testing of Ready-to-Eat

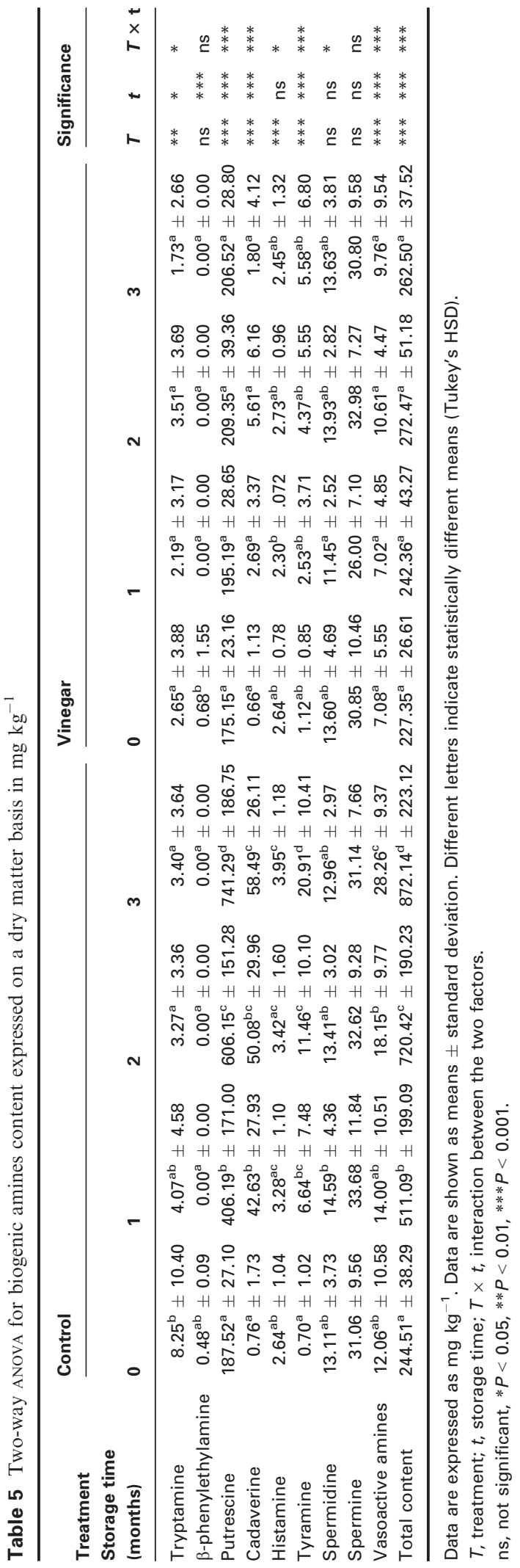


Foods Placed on the Market' (FSAI 2016), an 'extended shelf-life food products requiring refrigeration' may be classified as unsatisfactory when aerobic colony counts are $\geq 8 \log \mathrm{cfu} \mathrm{g}^{-1}$. After 3 months of storage, our results remained between 6 and $8 \log \mathrm{cfu} \mathrm{g}^{-1}$ allowing us to consider them as borderline (FSAI 2016).

Other authors, studying pork sausage patties have reported a decrease in total plate counts with vinegar; however, their values after 18 days are higher than our after 3 months in both control and vinegar samples (Bradley et al., 2011).

\section{Biogenic amines profile}

The results regarding the content in biogenic amines are summarised in Table 5. Putrescine is by far the most abundant biogenic amine, with contents between 175.15 and $741.29 \mathrm{mg} \mathrm{kg}^{-1}$. On the contrary, $\beta$-phenylethylamine is the less abundant amine, only detected at time zero (T0), with mean values of $0.48 \mathrm{mg} \mathrm{kg}^{-1}$ in control samples and $0.68 \mathrm{mg} \mathrm{kg}^{-1}$ in vinegar samples.

Significant differences were observed between treatments for most individual biogenic amines, with the exception of $\beta$-phenylethylamine, spermine and spermidine. Furthermore, spermine and spermidine contents remained more or less constant throughout the storage period.

Tryptamine values generally decreased with time for both control and vinegar samples $(P<0.05)$. On the other hand, putrescine, cadaverine and tiramine contents increased with time for both treatments $(P<0.001)$. Histamine values remained mostly unchanged with time.

Tyramine and histamine are biogenic amines with toxic effects like headaches, hypertension and perspiration in levels of $50 \mathrm{mg}$ per person per meal (EFSA 2011). On the other hand, putrescine is not toxic, but it potentiates the toxic effects of other biogenic amines, such as histamine (Chinnici et al., 2016). In our study, the levels of these amines always remained below this threshold, although their contents are lower in vinegar samples, which is very important for consumer health issues.

According to Nuñez et al. (2016), food products that contain more than $500 \mathrm{mg} \mathrm{kg}^{-1}$ histamine and $1000 \mathrm{mg} \mathrm{kg}^{-1}$ tyramine are considered toxic or dangerous to human health. However, for susceptible individuals or individuals whose health is compromised, these are far too high levels (Stadnik \& Dolatowski, 2010). In fact, according to Karovičová \& Kohajdová (2005), levels as low as $5-10 \mathrm{mg} \mathrm{kg}^{-1}$ of histamine may be harmful for susceptible individuals. On the other hand, for $\beta$-phenylethylamine, there are evidences that a content of $30 \mathrm{mg} \mathrm{kg}^{-1}$ in food products may be toxic (Gardini et al., 2001).

Vinegar samples showed significantly lower contents in vasoactive amines throughout the storage period $(P<0.001)$. The reduced content in biogenic amines of vinegar treated samples might be explained by the significantly lower enterobacterial counts in vinegar samples. Furthermore, these results seem to indicate that the microbiota present in these samples might be mostly decarboxylase-negative. Nevertheless, these are high values for biogenic amines, considering that it is a cooked RTEMP and not a fermented meat product (Ruiz-Capillas \& Jimenez-Colmenero, 2004).

\section{Sensory evaluation}

The attributes evaluated by the panel in the different sensory sessions are presented in Table 6. Samples contaminated with L. monocytogenes were not subjected to a full sensory evaluation by the panellists. In

Table 6 Sensory analysis data

\begin{tabular}{|c|c|c|c|c|c|c|c|c|}
\hline \multirow{2}{*}{$\begin{array}{l}\text { Treatment } \\
\text { Storage time (months) }\end{array}$} & \multicolumn{4}{|l|}{ Control } & \multicolumn{4}{|l|}{ Vinegar } \\
\hline & 0 & 1 & 2 & 3 & 0 & 1 & 2 & 3 \\
\hline Colour intensity & $62.26 \pm 15.25$ & $63.02 \pm 13.39$ & $57.29 \pm 13.95$ & $55.92 \pm 14.19$ & $60.46 \pm 17.51$ & $58.44 \pm 16.85$ & $55.17 \pm 16.54$ & $56.83 \pm 17.82$ \\
\hline Off-colours & $2.48 \pm 8.59$ & $0.83 \pm 2.98$ & $3.08 \pm 7.95$ & $3.75 \pm 8.96$ & $2.24 \pm 8.01$ & $1.83 \pm 8.76$ & $2.38 \pm 4.78$ & $2.67 \pm 6.51$ \\
\hline Marbled & $56.02 \pm 18.26$ & $61.50 \pm 17.58$ & $52.25 \pm 23.03$ & $54.00 \pm 16.06$ & $58.37 \pm 18.27$ & $60.81 \pm 19.02$ & $55.08 \pm 17.06$ & $52.75 \pm 19.23$ \\
\hline Aroma intensity & $60.93 \pm 16.10$ & $61.96 \pm 14.31$ & $59.83 \pm 16.24$ & $53.58 \pm 13.07$ & $63.72 \pm 15.17$ & $60.40 \pm 18.22$ & $58.17 \pm 16.03$ & $62.25 \pm 11.63$ \\
\hline Off-aromas & $4.24 \pm 13.18$ & $2.65 \pm 8.00$ & $7.92 \pm 14.70$ & $11.36 \pm 9.60$ & $0.74 \pm 2.06$ & $0.79 \pm 1.68$ & $2.58 \pm 5.59$ & $8.75 \pm 11.66$ \\
\hline Hardness & $49.74 \pm 11.23$ & $50.72 \pm 7.61$ & $50.83 \pm 2.04$ & * & $46.83 \pm 10.17$ & $45.54 \pm 8.84$ & $46.58 \pm 11.70$ & $*$ \\
\hline Fibrousness & $22.52 \pm 20.77$ & $29.38 \pm 20.81$ & $13.17 \pm 10.87$ & * & $21.02 \pm 19.28$ & $25.44 \pm 20.45$ & $22.71 \pm 19.51$ & $*$ \\
\hline Succulence & $59.83 \pm 15.81$ & $59.09 \pm 14.20$ & $61.00 \pm 17.79$ & * & $62.87 \pm 17.05$ & $66.63 \pm 12.38$ & $66.08 \pm 14.20$ & $*$ \\
\hline Flavour intensity & $63.15 \pm 12.43$ & $63.22 \pm 10.85$ & $55.67 \pm 10.33$ & * & $67.15 \pm 10.62$ & $65.91 \pm 10.31$ & $64.79 \pm 10.97$ & $*$ \\
\hline Off-flavours & $5.07 \pm 15.78$ & $1.26 \pm 2.21$ & $4.67 \pm 8.16$ & $*$ & $2.41 \pm 8.04$ & $3.55 \pm 11.51$ & $0.58 \pm 1.28$ & $*$ \\
\hline Salt perception & $52.13 \pm 9.75$ & $51.53 \pm 7.65$ & $52.83 \pm 5.60$ & * & $50.80 \pm 6.96$ & $52.25 \pm 7.25$ & $52.46 \pm 8.44$ & $*$ \\
\hline Overall appreciation & $62.78 \pm 15.16$ & $61.50 \pm 13.65$ & $62.50 \pm 18.32$ & * & $67.59 \pm 13.12$ & $64.13 \pm 12.31$ & $63.88 \pm 12.61$ & $*$ \\
\hline
\end{tabular}

Data are expressed as means \pm standard deviation.

*Samples were not tasted due to the presence of Listeria monocytogenes. 
these samples, the evaluation only concerned the analysis of colour and aroma, and not the analysis of flavour and texture. No significant differences were observed between treatments or throughout storage. However, regarding succulence, flavour intensity and overall appreciation tasters preferred vinegar samples (Table 6). Regarding overall appreciation, the differences between treatments are not significant and become less pronounced throughout storage time. Offaromas and off-flavours are less detected in vinegar samples, suggesting that vinegar can mask some defects (Table 6). Furthermore, it is important to notice that no vinegar off-aromas and off-flavours were recorded by tasters. When preservatives like organic acids, such as vinegar, are used, it is necessary to ensure that they have no negative impact on the product regarding organoleptic quality, as has been described before (Smulders \& Greer, 1998). However, this was not the case in our products, since overall appreciation values were higher for vinegar samples.

\section{Conclusions}

The use of vinegar in the manufacture of a traditional RTEMP significantly improved food quality and hazard control, based on microbiological analyses and biogenic amines content. Furthermore, vinegar did not depreciate sensory acceptability. In fact, although no significant differences were observed, vinegar samples were generally scored with higher values regarding overall appreciation.

Based on these results, and considering that there were no significant differences in the microbial counts between 1 and 3 months storage, we propose the extension of the shelf-life period from 1 to 3 months.

Additionally, this kind of RTEMP appears to be contaminated from the handling by food operators in the after cooking processing and before packaging. Therefore, we suggest a post-packaging pasteurisation of the product before commercialisation. This would ensure food safety and could extend the shelf-life even further.

To our knowledge, there are very few studies on this kind of sliced RTEMP, which is a sort of galantine, but more studies are needed in the future to valorise them. In fact, these traditional RTEMP are manufactured with low value meat pieces, such as pork heads, but may be highly valorised by consumers due to their particularly appreciated sensory characteristics that regard them as delicatessens and are willing to pay for them.

\section{Acknowledgments}

The authors acknowledge financial support provided by PRODER 13.021 (QREN/PRODER/Medida 4.1).
This work is also funded by National Funds through FCT - Fundação para a Ciência e a Tecnologia under Project UID/AGR/00115/2013. M. Laranjo (SFRH/ $\mathrm{BPD} / 108802 / 2015$ ) and R. Garcia (SFRH/BPD/ 109912/2015) acknowledge Post-Doc research grants from FCT. The authors thank Paladares Alentejanos, Lda. for their collaboration and A. Oliveira and G. Pias for their technical assistance.

\section{Conflict of interest}

The authors declare that there are no conflicts of interest.

\section{References}

Barbuddhe, S.B., Malik, S.V.S., Kumar, J.A., Kalorey, D.R. \& Chakraborty, T. (2012). Epidemiology and risk management of listeriosis in India. International Journal of Food Microbiology, 154, 113-118.

Bradley, E.M., Williams, J.B., Schilling, M.W. et al. (2011). Effects of sodium lactate and acetic acid derivatives on the quality and sensory characteristics of hot-boned pork sausage patties. Meat Science, 88, 145-150.

Budak, N.H., Aykin, E., Seydim, A.C., Greene, A.K. \& Guzel-Seydim, Z.B. (2014). Functional properties of vinegar. Journal of Food Science, 79, R757-R764.

Chang, J.-M. \& Fang, T.J. (2007). Survival of Escherichia coli O157: H7 and Salmonella enterica serovars typhimurium in iceberg lettuce and the antimicrobial effect of rice vinegar against E. coli O157: H7. Food Microbiology, 24, 745-751.

Chen, H., Chen, T., Giudici, P. \& Chen, F. (2016). Vinegar functions on health: constituents, sources, and formation mechanisms. Comprehensive Reviews in Food Science and Food Safety, 15, 1124-1138.

Chinnici, F., Durán-Guerrero, E. \& Riponi, C. (2016). Discrimination of some European vinegars with protected denomination of origin as a function of their amino acid and biogenic amine content. Journal of the Science of Food and Agriculture, 96, 3762-3771.

Costell, E. \& Durán, L. (1981a). El análisis sensorial en el control de calidad de los alimentos. I - Introduccion. Revista de Agroquimica y Tecnologia de Alimentos, 21, 1-10.

Costell, E. \& Durán, L. (1981b). El análisis sensorial en el control de calidad de los alimentos. II - Planteamiento y planificación: selección de pruebas. Revista de Agroquimica y Tecnologia de Alimentos, 21, 149-166.

Costell, E. \& Durán, L. (1981c). El análisis sensorial en el control de calidad de los alimentos. III - Planificacion, selección de jueces y diseño estatistico. Revista de Agroquimica y Tecnologia de Alimentos, 21, 455-470.

Costell, E. \& Durán, L. (1981d). El análisis sensorial en el control de calidad de los alimentos. IV- Realización y análisis de los datos. Revista de Agroquimica y Tecnologia de Alimentos, 22, 10-21.

Cui, H., Gabriel, A.A. \& Nakano, H. (2010). Antimicrobial efficacies of plant extracts and sodium nitrite against Clostridium botulinum. Food Control, 21, 1030-1036.

EC (2007). Commission Regulation (EC) No. 1441/2007 of 5 December 2007 on microbiological criteria for foodstuffs. Official Journal of the European Union, L 322, 12-29.

EC (2011). Commission Regulation (EC) No. 1169/2011 of of 25 October 2011 on the provision of food information to consumers. Official Journal of the European Union, L 304, 18-63.

EFSA. (2011). Scientific Opinion on risk based control of biogenic amine formation in fermented foods. EFSA Panel on Biological Hazards (BIOHAZ). EFSA Journal, 9, 1-93. 
Elias, M. (2004). Caracterização, Conservação e Produção Biotecnológica de Paio de Porco Alentejano. Pp. 367. Évora: Departamento de Fitotecnia, Universidade de Évora.

Fraqueza, M.J., Ferreira, M.C. \& Barreto, A.S. (2008). Spoilage of light (PSE-like) and dark turkey meat under aerobic or modified atmosphere package: microbial indicators and their relationship with total volatile basic nitrogen. British Poultry Science, 49, 1220.

FSAI (2016). Guidelines for the interpretation of results of microbiological testing of ready-to-eat foods placed on the market. In: Guidance Note No. 3 (edited by Ireland, F. S. A. O.). Dublin, Ireland: FSAI.

García-Díez, J., Alheiro, J., Pinto, A.L. et al. (2016). Behaviour of food-borne pathogens on dry cured sausage manufactured with herbs and spices essential oils and their sensorial acceptability. Food Control, 59, 262-270.

García-Díez, J., Alheiro, J., Falco, V., Fraqueza, M.J. \& Patarata, L. (2017). Chemical characterization and antimicrobial properties of herbs and spices essential oils against pathogens and spoilage bacteria associated to dry-cured meat products. Journal of Essential Oil Research, 29, 117-125.

Gardini, F., Martuscelli, M., Caruso, M.C. et al. (2001). Effects of $\mathrm{pH}$, temperature and $\mathrm{NaCl}$ concentration on the growth kinetics, proteolytic activity and biogenic amine production of Enterococcus faecalis. International Journal of Food Microbiology, 64, 105-117.

Henriques, A.R., Gama, L.T. \& Fraqueza, M.J. (2017). Tracking Listeria monocytogenes contamination and virulence-associated characteristics in the ready-to-eat meat-based food products industry according to the hygiene level. International Journal of Food Microbiology, 242, 101-106.

Herrero, A.M., de la Hoz, L., Ordóñez, J.A., Herranz, B., Romero de Ávila, M.D. \& Cambero, M.I. (2008). Tensile properties of cooked meat sausages and their correlation with texture profile analysis (TPA) parameters and physico-chemical characteristics. Meat Science, 80, 690-696.

ISO (1973). Meat and meat products - Determination of total fat content.

ISO (1978). Meat and meat products - Determination of nitrogen content (Reference method).

ISO (1993). ISO 8586-1. Sensory analysis-General guidance for the selection, training and monitoring of assessors-Part 1: Selected assessors.

ISO (1997). Meat and meat products - Determination of moisture content (Reference method).

ISO (1998). Meat and meat products - Determination of total ash.

ISO (1999). Meat and meat products. Determination of the pH (Reference method)

ISO (2001). Microbiology of food and animal feeding stuffs - Horizontal method for the enumeration of psychrotrophic microorganisms.

ISO (2008). Microbiology of food and animal feeding stuffs - Horizontal method for the enumeration of yeasts and moulds - Part 2: Colony count technique in products with water activity less than or equal to 0,95 .

ISO (2013). Microbiology of the food chain - Horizontal method for the enumeration of microorganisms - Part 1: Colony count at 30 degrees $\mathrm{C}$ by the pour plate technique.

ISO (2014). Microbiology of the food chain - Horizontal method for the detection and enumeration of Listeria monocytogenes and of Listeria spp. - Part 2: Enumeration method.

ISO (2017a). Animal and vegetable fats and oils - Determination of peroxide value - Iodometric (visual) endpoint determination.

ISO (2017b). Microbiology of the food chain-Horizontal method for the detection and enumeration of Enterobacteriaceae-Part 2: Colony-count technique.
Karovičová, J. \& Kohajdová, Z. (2005). Biogenic amines in food. Chemical Papers, 59, 70-79.

Kim, E. \& Choi, J. (2015). The evaluation of metabolizable energy in traditional Korean food for protein sources. Journal of Ethnic Foods, 2, 179-185.

Laranjo, M., Agulheiro-Santos, A.C., Potes, M.E. et al. (2015). Effects of genotype, salt content and calibre on quality of traditional dry-fermented sausages. Food Control, 56, 119-127.

Laranjo, M., Gomes, A., Agulheiro-Santos, A.C. et al. (2016a). Characterisation of "Catalão" and "Salsichão" Portuguese traditional sausages with salt reduction. Meat Science, 116, 34-42.

Laranjo, M., Gomes, A., Potes, M.E., Fernandes, M.J., Fraqueza, M.J. \& Elias, M. (2016b). Development of a long-life vacuumpackaged ready-to-eat meat product based on a traditional Portuguese seasoned meat. International Journal of Food Science \& Technology, 51, 1150-1158.

Mateus, T., Maia, R.L. \& Teixeira, P. (2014). Awareness of listeriosis among Portuguese pregnant women. Food Control, 46, 513-519.

Nuñez, M., del Olmo, A. \& Calzada, J. (2016). Biogenic amines. In: Encyclopedia of Food and Health (edited by B. Caballero, P.M. Finglas \& F. Toldrá). Pp. 416-423. Oxford: Academic Press.

Over, K.F., Hettiarachchy, N., Johnson, M.G. \& Davis, B. (2009). Effect of Organic Acids and Plant Extracts on Escherichia coli O157:H7, Listeria monocytogenes, and Salmonella typhimurium in Broth Culture Model and Chicken Meat Systems. Journal of Food Science, 74, M515-M521.

Ruiz-Capillas, C. \& Jimenez-Colmenero, F. (2004). Biogenic amines in meat and meat products. Critical Reviews in Food Science and Nutrition, 44, 489-499.

Shan, B., Cai, Y.-Z., Brooks, J.D. \& Corke, H. (2009). Antibacterial and antioxidant effects of five spice and herb extracts as natural preservatives of raw pork. Journal of the Science of Food and Agriculture, 89, 1879-1885.

Smulders, F.J.M. \& Greer, G.G. (1998). Integrating microbial decontamination with organic acids in HACCP programmes for muscle foods: prospects and controversies. International Journal of Food Microbiology, 44, 149-169.

Stadnik, J. \& Dolatowski, Z.J. (2010). Biogenic amines in meat and fermented meat products. Acta Scientiarum Polonorum Technologia Alimentaria, 9, 251-263.

Stelzleni, A.M., Ponrajan, A. \& Harrison, M.A. (2013). Effects of buffered vinegar and sodium dodecyl sulfate plus levulinic acid on Salmonella Typhimurium survival, shelf-life, and sensory characteristics of ground beef patties. Meat Science, 95, 1-7.

Tajkarimi, M.M., Ibrahim, S.A. \& Cliver, D.O. (2010). Antimicrobial herb and spice compounds in food. Food Control, 21, 11991218 .

Wood, J.D., Richardson, R.I., Nute, G.R. et al. (2003). Effects of fatty acids on meat quality: a review. Meat Science, 66, 21-32.

Xi, J., Shen, D., Li, Y. \& Zhang, R. (2011a). Ultrahigh pressure extraction as a tool to improve the antioxidant activities of green tea extracts. Food Research International, 44, 2783-2787.

Xi, Y., Sullivan, G.A., Jackson, A.L., Zhou, G.H. \& Sebranek, J.G. (2011b). Use of natural antimicrobials to improve the control of Listeria monocytogenes in a cured cooked meat model system. Meat Science, 88, 503-511.

Xi, Y., Sullivan, G.A., Jackson, A.L., Zhou, G.H. \& Sebranek, J.G. (2012). Effects of natural antimicrobials on inhibition of Listeria monocytogenes and on chemical, physical and sensory attributes of naturally-cured frankfurters. Meat Science, 90, 130-138.

Zhang, H., Kong, B., Xiong, Y.L. \& Sun, X. (2009). Antimicrobial activities of spice extracts against pathogenic and spoilage bacteria in modified atmosphere packaged fresh pork and vacuum packaged ham slices stored at $4^{\circ} \mathrm{C}$. Meat Science, 81, 686-692. 